\title{
The Importance of External Grant Support for a Public College of Arts and Science
}

\author{
Joseph E. Steinmetz, Dean \\ College of Liberal Arts and Sciences \\ University of Kansas
}

$\mathrm{T}$

he punch line of this paper is easy to state at the very outset because it is obvious - external grant support is vital for the operation of a College of Arts and Sciences at a Research I level public institution of higher education like the University of Kansas. External grant support of research provides a great deal of the funds that are necessary for members of the faculty to explore their research and scholarship. External grant support provides funds for the training of graduate students, the next generation of scholars and researchers. And, external grant support often provides the means for introducing undergraduate students to the world of research and scholarly pursuits.

In many large, state-supported institutions of higher education, the College of Arts and Sciences is the largest unit, containing the most faculty and responsible for teaching the majority of credit hours at both the undergraduate and graduate levels. In many ways, the undergraduate missions of colleges of arts and sciences at large state institutions is the same as the institutional missions of smaller liberal arts colleges like Grinnell, DePauw, or Williams: To expose undergraduates to a wide variety of academic subjects that include the humanities, social sciences, and natural and mathematical sciences. In addition, to the goal liberal arts and science colleges at Research I institutions provide another important experience for undergraduates-exposure to a variety of research and creative activities that involve members of the faculty as well as postdoctoral scholars and graduate students. Generally, arts and science college students are exposed to a general education curriculum that builds problem solving skills and fosters creativity while preparing students for change. While majors and minors are earned, colleges of arts and sciences do not stress the development of disciplinespecific skills, as is the case for professional schools on campus, but rather generalized academic skills that should enhance the students' chances for success after graduation.

Colleges of arts and sciences at large public institutions make a number of contributions to higher education. They teach many, many undergraduates in a wide variety of disciplines, students who make up the majority of society's future scientists, mathematicians, humanists, and social scientists. Colleges of arts and sciences at Research I institutions also offer a variety of graduate programs in many different departments. These graduate students contribute to the individual research programs of countless scholars while 
also making novel contributions to the scholarly literatures in their respective fields. They also actively participate in the teaching of undergraduates. Important for the present discussion, faculty and students of colleges of arts and sciences in public institutions provide much of the research, scholarship and creative activity that form the bases of inquiry and the gathering and disseminating knowledge.

Given the large commitments to undergraduate and graduate teaching, faculty appointments in colleges of arts and sciences are quite different than in medical schools and research centers or institutes. Generally, a 40-40-20 researchteaching-service model is applied where it is assumed that $40 \%$ of a faculty member's time is spent in research, $40 \%$ in teaching, and $20 \%$ in local and national service. How the $40 \%$ time in teaching is spent can vary greatly across units in a college, generally related to how research and scholarship is carried out. For example, in the bench sciences, such as biology or chemistry, teaching loads are typically 1-2 formal courses per year while in the humanities, such as history or philosophy, the teaching load is typically 4 per year. In general, 100\% of the faculty member's salary is paid from public sources, although teaching reductions are sometimes awarded when salary is underwritten by external grant funds (which, for the most part, are only available for the sciences and social sciences). There have been some recent challenges to this model. Many areas of the social sciences conduct research in a manner that makes it difficult to determine if teaching loads should be closer to the sciences or to the humanities and the introduction of a number of new interdisciplinary fields (e.g., behavioral neuroscience) has made it more difficult to define teaching loads. Inevitably, there are conflicts that arise between teaching and research. For example, scientists from colleges of arts and sciences often compete for grant funding with scientists from medical schools where teaching loads are lighter and more time is thus available for research.

The landscape of colleges of arts and sciences is hardly static, in part driven by national priorities for research and teaching. Recently, there has been a trend that favors the formation of larger interdisciplinary and multidisciplinary teams of investigators who study problems that used to be studied by individual investigators in the social sciences and natural and mathematical sciences. This trend has not for the most part affected the humanities with exception of areas like ethics and perhaps language and cultural studies. Recently, there has been a general building of the life sciences, in part because of the doubling of the NIH budget that has occurred over the past decade or so. The general perception in many institutions is that funding for some of the traditional areas of the social and behavioral sciences is down (e.g., some basic areas of social psychology). However, it appears that there is an increasing number of social and behavioral scientists who are conducting research with life scientists in both clinical and basic science domains. The jury is still out as to whether this is a good trend or a bad trend. For example, many social and behavioral scientists are 
concerned about the futures of their fields and wonder if the future of the behavioral and social sciences is being driven by the short term availability of federal funds rather than by issues of curiosity, good scholarship, and long range planning considerations.

The opening premise of this paper was that external grant support is extremely important for the future of colleges of arts and sciences. One might ask: What would the consequences be if a down-turn in external support for faculty in arts and sciences colleges occurred or if federal research priorities shifted dramatically? Loss of external research support has some obvious consequences. First, many wellestablished researchers would have difficulty maintaining their research programs - their programs would become smaller and more focused and this would likely result in fewer advances and slower progress on many important issues. Second, to internally fund research programs, institutions may be forced to divert funds from important areas of scholarship that are already under-funded, such as the humanities, from undergraduate education, and from funds earmarked for building and maintaining necessary research infrastructure. Third, graduate training would suffer as fewer dollars would be available for research conducted by our next generation of scholars. Fourth, undergraduate education would suffer because at Research I institutions many undergraduates participate directly in ongoing faculty and graduate student research. Fifth, we might create an academy that is made up of individuals and institutions that represent the "haves" (with support) and the "havenots" (without support) thus reducing the huge source of intellectual variation and diversity that exists between programs and institutions. There are also consequences for colleges of arts and sciences if research emphases and priorities abruptly change. Important areas of studies may disappear for lack of support as faculty are hired into areas thought to be of highest priority by external funding agencies. Indeed, almost all faculty in public colleges of arts and sciences are tenured or on tenure-track. Tenure, which is extremely important for maintaining academic freedom, makes quick changes in faculty composition nearly impossible to undertake. And, institutions made large investments to create existing faculties. These investments were made not only to establish research directions and priorities, but also to address the teaching necessary for delivering a comprehensive liberal arts and sciences education for the undergraduates.

Public institutions of higher education can take steps to ensure that research and scholarship flourish in colleges of arts and sciences. We should encourage the establishment of interdisciplinary and multidisciplinary centers, programs and departments that make use of the full range of talent we have as effectively as possible. We need to make sure that departments and programs keep up with current trends in their respective fields and disciplines so they are positioned well to take advantage of funding opportunities that present themselves in the future. We need to make sure that our 
undergraduate and graduate students are thoroughly prepared for careers that will inevitably change. We do not know for certain where the great research advancements will be in the future but we can provide our students with the skills necessary to help assess and identify the trends and directions. We need to find ways to seed faculty research for work in new areas and to bridge faculty research when funding levels are tight. Finally, we should design and build university infrastructure that emphasizes group participation in projects over individual laboratories and work-spaces; this will require a shift in culture for many institutions.

There are also things that federal funding agencies can do to ensure that research and scholarship continue to flourish. First, there seems to be a growing trend toward looking for all of the solutions to the world's problems in biology, chemistry and physics. Federal funding policy makers should recognize that not all problems in the world are best attacked from biological or physical science perspectives. That is, the potential contributions of social and behavioral scientists, computationalists and humanists are still great. Second, more funding should be provided for career changes so that our most productive and brightest scholars are "retooled" to enter new research areas. Third, emphasize interdisciplinary and multidisciplinary approaches for training grants and other funding opportunities that are made available to graduate students and postdoctoral scholars. Fourth, convince the skeptics in government that many disciplines in the arts and sciences are important and worthy of continued study. While it is easy to see why we should fund research on disease, weather patterns, or engineering, it is sometimes harder to see why studying history, social policy, ethics, or child behavior continues to be important. Finally, it is very important that university administrators and those at external funding agencies work more closely together to make sure that what is going on in the two spheres is maximally aligned and coordinated. There is a lot at stake here as our future rests largely with the students who currently occupy the seats in classrooms within our colleges of arts and sciences. It is very important that we are all on the same page. 